\title{
Work Sharing as a Metric and Productivity Indicator for Administrative Workflows ${ }^{\dagger}$
}

\author{
Charles Roberto Telles \\ Secretary of State for Education of Paraná, Curitiba, Brazil \\ + Presented at the Entropy 2021: The Scientific Tool of the 21st Century, 5-7 May 2021; Available online: \\ https://sciforum.net/conference/Entropy2021/.
}

Published: 5 May 2021

A mathematical method was developed to generate an indicator on the productivity of administrative complex workflows. The indicator can roughly and steadily reveal the definition of productivity as a state of endosectoral (among internal sector agents) and exosectoral (among external sector agents) administrative services sharing. The indicator can be used by public and private managers to measure human resource efficiency in proportion to work requests/inputs of all administrative services occurring in a given workflow.

Defining administrative workflow events as a nonlinear dynamics that assume a random ordered or disordered growth rate of information processing, a method has been proposed for large-scale administrative systems defined as structures of hybrid system variables (continuous or discrete), iterated and composed of fixed-point attracted events at which for all possible metric spaces solutions, the modeling of variables from Lyapunov exponential stability point of view allows the projection of system performance to be oriented, that is in other words, the relationship between the number of agents and the number of administrative services within an administrative workflow environment.

This definition differs from traditional or differentiated key performance indicators (KPI), such as working hours, medical certificate, per capita productivity, among others and the proposed methodology is only suitable for large-scale administrative activities that have a wide range of activities as well as the number of agents that perform them.

For system management purposes, it is possible to view the possibility of administrating system discretization, computerization and monitoring in order to be able to predict and validate the exponential function as a valid indicator of nonlinear systems where the results were defined by the amount of work sharing effect.

(C) 2021 by the author. Licensee MDPI, Basel, Switzerland. This article is an open access article distributed under the terms and conditions of the Creative Commons Attribution (CC BY) license (http://creativecommons.org/licenses/by/4.0/). 